\title{
Erratum to: Does Pregnancy Increase the Need for Revisional Surgery After Laparoscopic Adjustable Gastric Banding?
}

\author{
Rebecca N. Haward • Wendy A. Brown • \\ Paul E. O'Brien
}

Published online: 30 April 2011

(C) Springer Science+Business Media, LLC 2011

\section{Erratum to: OBES SURG}

DOI 10.1007/s11695-010-0235-7

The authors would like to amend the Conflict of Interest statement as it appears in the original publication.

Dr Wendy Brown reported receiving an honorarium from Allergan for attending a scientific advisory panel in London in 2009.

Dr Paul O'Brien reported having written a patient information book entitled "The LAP- BAND Solution: A Partnership for Weight Loss" which was published by Melbourne University Publishing in 2007. Most copies are given to patients without charge but he reports that he derives a financial benefit from the copies that are sold. He also reports receiving compensation as the national medical director of the American Institute of Gastric Banding, a multicenter facility, based in Dallas, Texas, that treats obesity predominantly by gastric banding.

No other authors reported disclosures.

The Centre for Obesity Research and Education (CORE) receives a grant from Allergan for research support. The grant is not tied to any specified research projects and Allergan have no control of the protocol, analysis and reporting of any studies. CORE also receives a grant from Applied Medical towards the educational programs.

The online version of the original article can be found at http://dx.doi. org/10.1007/s11695-010-0235-7.

R. N. Haward $(\bowtie) \cdot$ W. A. Brown · P. E. O’Brien

The Centre for Obesity Research and Education (CORE),

Monash University Medical School, The Alfred Hospital,

Melbourne 3004, Australia

e-mail: rhaward@gmail.com 